\title{
NMDA Receptor-Mediated Neuroprotective Effect of the Scutellaria baicalensis Georgi Extract on the Excitotoxic Neuronal Cell Death in Primary Rat Cortical Cell Cultures
}

\author{
Jinsong Yang, ${ }^{1}$ Xiaohong $W u,{ }^{2}$ Haogang Yu, ${ }^{1}$ Xinbiao Liao, ${ }^{1}$ and Lisong Teng ${ }^{3}$ \\ ${ }^{1}$ Department of Radiation Oncology, The First Affiliated Hospital, College of Medicine, Zhejiang University, Hangzhou 310003, China \\ ${ }^{2}$ Department of Physical Medicine \& Rehabilitation, The First Affiliated Hospital, College of Medicine, Zhejiang University, \\ Hangzhou 310003, China \\ ${ }^{3}$ Department of Surgical Oncology, The First Affiliated Hospital, College of Medicine, Zhejiang University, Hangzhou 310003, China
}

Correspondence should be addressed to Lisong Teng; tenglisong145@gmail.com

Received 10 January 2014; Accepted 4 April 2014; Published 21 May 2014

Academic Editor: Thomas E. Salt

Copyright (C) 2014 Jinsong Yang et al. This is an open access article distributed under the Creative Commons Attribution License, which permits unrestricted use, distribution, and reproduction in any medium, provided the original work is properly cited.

\begin{abstract}
The objective of the current research work was to evaluate the neuroprotective effect of the ethanol extract of Scutellaria baicalensis (S.B.) on the excitotoxic neuronal cell death in primary rat cortical cell cultures. The inhibitory effects of the extract were qualitatively and quantitatively estimated by phase-contrast microscopy and lactate dehydrogenase (LDH) assays. The extract exhibited a potent and dose-dependent inhibition of the glutamate-induced excitotoxicity in the culture media. Further, using radioligand binding assays, it was observed that the inhibitory effect of the extract was more potent and selective for the $\mathrm{N}$-methylD-aspartate (NMDA) receptor-mediated toxicity. The S.B. ethanol extract competed with $\left[{ }^{3} \mathrm{H}\right] \mathrm{MDL} 105,519$ for the specific binding to the NMDA receptor glycine site with $50 \%$ inhibition occurring at $35.1 \mu \mathrm{g} / \mathrm{mL}$. Further, NMDA receptor inactivation by the S.B. ethanol extract was concluded from the decreasing binding capability of $\left[{ }^{3} \mathrm{H}\right] \mathrm{MK}-801$ in the presence of the extract. Thus, S.B. extract exhibited neuroprotection against excitotoxic cell death, and this neuroprotection was mediated through the inhibition of NMDA receptor function by interacting with the glycine binding site of the NMDA receptor. Phytochemical analysis of the bioactive extract revealed the presence of six phytochemical constituents including baicalein, baicalin, wogonin, wogonoside, scutellarin, and Oroxylin A.
\end{abstract}

\section{Introduction}

N-Methyl-D-aspartate (NMDA) receptors have a welldefined role in neuronal plasticity. Excitotoxic neuronal cell death can occur if these receptors are overactivated. As such, NMDA antagonists (NMDA inhibitors) are thought to play a crucial role in neuroprotection. However, it has been reported that NMDA receptors also have an important role in enhancing neuronal survival. Thus, it follows that NMDAR antagonists not only will protect from excitotoxicity but would also reduce prosurvival activity of NMDAR. Hence, the recognition of the switches regulating prosurvival visà-vis proexcitotoxic outcome of NMDAR stimulation may lead to development of NMDAR antagonists that specifically block the excitotoxicity while augmenting the protective
NMDAR signaling. Glutamate is the principal excitatory neurotransmitter in the CNS. It stimulates various types of receptors including the N-methyl-D-aspartate receptors (NMDAR). NMDAR form calcium-permeable ion channels and are principal mediators of the excitotoxic cell death following excessive release of glutamate after different forms of CNS insults [1-5].

Scutellaria baicalensis (Labiatae family) is a plant sometimes referred to as Huang Qin or Scutellariae radix (root). Scutellaria baicalensis (Chinese skullcap) is a traditional Chinese medicine for the purposes of cardiovascular and cognitive health as well as longevity [6-8]. It has been reported to possess strong neuroprotective properties. Scutellaria baicalensis is a component of various combination therapies (from TCM) including Ger-Gen-Chyn-Tang [9], 
Soshiho-tang [10], and Shuanghuanglian [11]. Various phytochemical components have been identified in S. baicalensis aerial and root parts. Baicalin (baicalein-7-glucoronide) and its aglycone baicalein as well as another glycoside known as baicalein-7-O-glucoside have been reported in S. baicalensis. In addition, wogonoside (wogonin-7-glucuronide) and its aglycone wogonin as well as another glycoside known as wogonin-5-O-glucoside have also been reported in it. Some other phytoconstituents reported in S. baicalensis are Oroxylin (5,7-dihydroxy-6-methoxyflavone) and its glucoside, neobaicalein, scutellarin, and isoscutellarin; chrysin; skullcap flavone; apigenin; luteolin; 6-hydroxyluteolin, and so forth [12-16].

The phytochemicals present in Scutellaria species have been reported to show a range of neuroprotective effects. Wogonin inhibited inflammatory activation of microglia by reduced cytotoxicity towards cocultured PC-12 neurons, supporting an in vitro neuroprotective role of this flavonoid. The efficacy of wogonin was further demonstrated in two experimental brain injury models. In the 4 -vessel occlusion model of transient global ischemia, wogonin decreased the death rate of hippocampal neurons, the induction of iNOS, and TNF- $\beta$ in hippocampus, whereas, in the kainate injection model, this flavonoid markedly protected from excitotoxic brain injury. Similarly, baicalein attenuated the NO production by suppressing iNOS induction, in LPS-activated BV-2 mouse microglial cells, besides reducing apoptotic cell death and NF-kB activation [17-19].

\section{Materials and Methods}

2.1. Materials. The plant material (roots) of Scutellaria baicalensis was collected from a local region of Hangzhou and was authenticated by a well-known botanist. Minimum essential medium (MEM), horse serum, and fetal calf serum were obtained from Gibco. Multiwell plates were bought from Falcon. Laminin, poly-L-lysine, L-glutamine, Glu, glucose, NMDA, polyethylenimine, and cytosine arabinoside were purchased from Merck. [ $\left.{ }^{3} \mathrm{H}\right] \mathrm{MDL} 105,519$ and $\left[{ }^{3} \mathrm{H}\right] \mathrm{MK}-$ 801 were purchased from Amersham Biosciences, Inc., and MOLEKULA Ltd., respectively. All other chemicals were of reagent grade.

2.2. Preparation of the Extract. The roots of the plant were thoroughly washed with tap water, shade dried, and then chopped into small pieces. Ethanol (95\%) was used for hot extraction which was carried out for 4 hours using a soxhlet extraction apparatus. The extract was then concentrated under reduced pressure in a rotary evaporator at $40^{\circ} \mathrm{C}$ and was then kept in a refrigerator at $4^{\circ} \mathrm{C}$ prior to use.

2.3. Primary Rat Cortical Neuronal Cultures. Primary rat cortical neuronal cultures were obtained from SpragueDawley (SD) rat embryos at embryonic stage of 14-16 days (Experimental Animal Centre of Sichuan University, Chengdu City, Sichuan Province, China). The rats used in the experiment weighed between 250 and $300 \mathrm{~g}$. The cerebral cortices were dissected and mechanically dissociated into single cells by trituration through Pasteur pipettes. Cells were plated at a density of $6 \times 10^{5}$ cells per well on 24 -well culture plates coated with Laminin and poly-L-lysine. Then, the cell cultures were incubated at $37^{\circ} \mathrm{C}$ in a humidified atmosphere of $5 \% \mathrm{CO}_{2}$ in an MEM containing medium supplemented with glucose $(25 \mathrm{mM})$, fetal calf serum $(5 \%)$, horse serum (5\%), and glutamine ( $5 \mathrm{mM})$. After $14-16$ days in the culture medium, the cells were used for the experiment.

2.4. Induction of Neuronal Cell Excitotoxicity and Their Assessment. Earle's balanced salt solution (EBSS) was used to rinse the cultured neuronal cells before the excitotoxic injuries were induced by exposure to $350 \mu \mathrm{M}$ NMDA or Glu concentration in $\mathrm{Mg}^{2+}$-free EBSS for $20 \mathrm{~min}$. After the induction of excitotoxicity, the neuronal cultures were rinsed and maintained at $37^{\circ} \mathrm{C}$ for $20-24$ hours in glucose supplemented MEM. Then, the neuronal cell cultures were treated for $30 \mathrm{~min}$ with $350 \mu \mathrm{M}$ NMDA or Glu in the presence of $1,10,25,50$, and $100 \mu \mathrm{g} / \mathrm{mL}$ concentrations of the extract in order to assess the effect of the S.B. ethanol extract on NMDA or Glu-induced neuronal injury. Stock sample solutions of the ethanol extract were prepared in dimethyl sulfoxide (DMSO). Lactate dehydrogenase (LDH) assay and phasecontrast microscopy were used to estimate quantitative and qualitative extent of the neuronal damage, respectively. As described previously [20], neuronal damage quantification was estimated by measuring lactate dehydrogenase (LDH) activity released into the culture medium. Background LDH release was determined by using sister neuronal cultures in each experiment and then subtracted from the values. The final concentration of the vehicle (not more than $0.5 \%$ ) exhibited no effect on cell excitotoxicity.

2.5. Synaptic Membranes for Receptor Binding Studies. For receptor binding studies, the synaptic membranes were prepared from forebrains of male Sprague-Dawley rats as reported earlier [21]. After centrifugation, the forebrains were homogenized at $1500 \times \mathrm{g}$ for $15 \mathrm{~min}$. The supernatant was collected and centrifuged at $3000 \times \mathrm{g}$ for $30 \mathrm{~min}$. The pellet stored at $-70^{\circ} \mathrm{C}$ overnight was liquefied at room temperature and then again suspended in $25 \mathrm{mM}$ Tris-acetate (PH 7.0) containing $0.05 \%$ Triton X-100. The solution was incubated at $37^{\circ} \mathrm{C}$ for $15 \mathrm{~min}$ and centrifuged at $4000 \times \mathrm{g}$ for $15 \mathrm{~min}$. Finally, the pellet was resuspended to give a protein concentration of $1.5 \mathrm{mg} / \mathrm{mL}$, determined by DC Protein Assay Kit (Bio-Rad).

2.6. Binding Studies with $\left[{ }^{3} \mathrm{H}\right] \mathrm{MDL}$ 105,519. $\left[{ }^{3} \mathrm{H}\right] \mathrm{MDL}$ 105,519 binding assay was carried out in 96-well plates. Incubation of the synaptic membranes $(25 \mu \mathrm{g} /$ well $)$ at $25^{\circ} \mathrm{C}$ for $20 \mathrm{~min}$ in a mixture containing $4 \mathrm{nM}\left[{ }^{3} \mathrm{H}\right] \mathrm{MDL} 105,519$ and different concentrations of the S.B. extract along with $25 \mathrm{mM}$ Tris-acetate was carried out. This reaction mixture was then washed thoroughly with the $0.6 \mathrm{~mL}$ of ice-cold $25 \mathrm{mM}$ Tris-acetate buffer by filtration using Whatman GF/A glass fiber filter. Then, the filter was wrapped with MeltiLex, sealed in a sample bag, and then counted by MicroBeta TriLux (Microplate Scintillation and Luminescence Counter, PerkinElmer) at a counting efficiency of 30-40\%. Nonspecific 


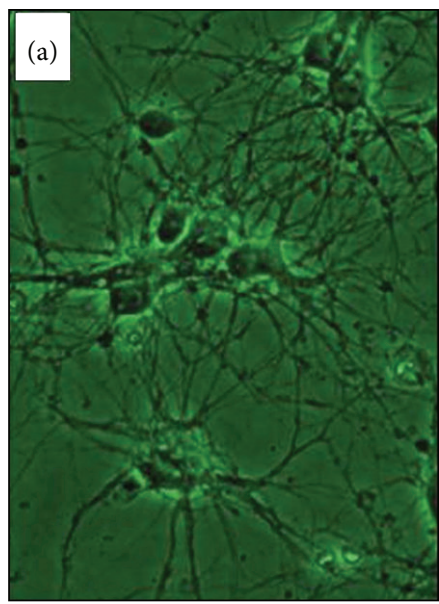

(a)

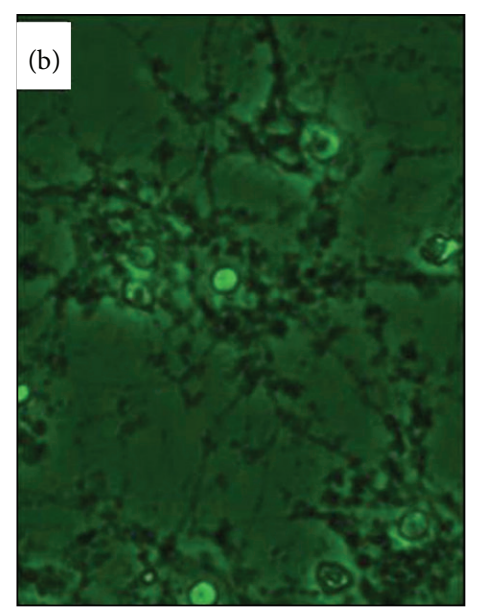

(b)

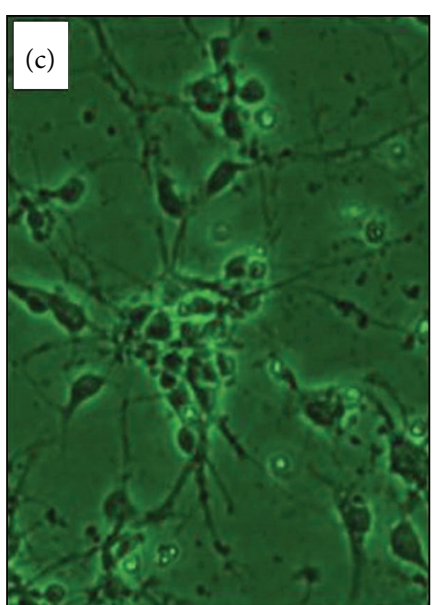

(c)

FIGURE 1: High magnification $(\times 400)$ photomicrographs of cultured embryonic cortical neuronal cells from 14 - to 16-day-old rats (in vitro); normal group (untreated). The nuclear membranes are distinct, and the dendrocyte is normal [1]. Glu-[350 $\mu \mathrm{M} \mathrm{for} 20 \mathrm{~min}$ in $\mathrm{Mg}^{2+}$-free $\mathrm{EBBS}$ and incubated for $20-24 \mathrm{~h}$ at $37^{\circ} \mathrm{C}$ in MEM supplemented with glucose] treated group, showing cellular swelling; dendrocyte is breaking and the nuclear shape is indistinct [2]. Glutamate-treated group in presence of S. baicalensis $(100 \mu \mathrm{g} / \mathrm{mL})$ extract and maintained as above [3]; note that the cellular shape is generally regular almost like that of untreated group.

binding, which was determined in the presence of $1 \mathrm{mM}$ glycine, was less than $10 \%$ of total binding.

2.7. Binding Studies with $\left.{ }^{3} H\right] M K-801$. For this purpose, the synaptic membranes $(25 \mu \mathrm{g} / \mathrm{mL})$ were incubated for $40 \mathrm{~min}$ in a $2 \mathrm{~mL}$ reaction mixture containing $4 \mathrm{nM}\left[{ }^{3} \mathrm{H}\right] \mathrm{MK}-801$, $0.2 \mu \mathrm{M}$ Glu, $2 \mathrm{mM}$ glycine, and different concentrations of the ethanol S.B. extract along with $25 \mathrm{mM}$ Tris-acetate buffer $(\mathrm{PH}$ 7.0). Then, the reaction was terminated by filtering through Whatman GF/B glass fiber filter and the bound radioactivity was determined by a liquid scintillation counter (Hidex 300 SL, USA) at a counting efficiency of 50-55\%. Nonspecific binding, determined in the presence of $200 \mu \mathrm{M}$ MK-801, was less than $10 \%$ of the total binding.

\section{Liquid Chromatography-Tandem Mass Spectrometry (LC-ESI-MSMS)/HPLC Analysis}

LC-MS equipment (LC-MS QqQ-6410B Agilent Technologies) consisted of a chromatographic system coupled with an Agilent Triple Quad mass spectrometer fitted with an ESI source. MS conditions were the following: nebulizer gas $45 \mathrm{Psi}$, gas temperature $325^{\circ} \mathrm{C}$, capillary voltage $4000 \mathrm{~V}$, and MS range $100-1200 \mathrm{Da}$; MSn spectra were obtained using both positive and negative modes.

HPLC analysis was carried out by an Agilent 1260 infinity series. A Chromolith RP-18e column (4.6 mm ID, $50 \mathrm{~mm}$ length) (Merck) was used. Gradient elution of the samples was performed using $0.1 \%$ formic acid (eluent $\mathrm{A}$ ) and methanol (eluent B). The gradient elution initial conditions were $45 \%$ of eluent B with linear gradient to $60 \%$ from 2 to $10 \mathrm{~min}$, followed by linear gradient to $70 \%$ of eluent B at $35 \mathrm{~min}$, and then linear gradient to $99 \%$ of eluent B at $38 \mathrm{~min}$, with this proportion being maintained for $2 \mathrm{~min}$. The column was then returned to the initial condition at $40 \mathrm{~min}$ and maintained until the end of the run at $42 \mathrm{~min}$. The flow rate was $1 \mathrm{~mL} / \mathrm{min}$. The sample injection volume was $10 \mu \mathrm{L}$.

3.1. Statistical Analysis. The experiments were done in triplicate and the data were processed by nonlinear regression analysis using GraphPad software, USA, for the calculation of $\mathrm{IC}_{50}$ values. All the results were expressed as mean \pm SEM. Statistical significance was considered at $P \leq 0.05$.

\section{Results}

4.1. Assessment of Neuronal Excitotoxicity. After the exposure of cultured rat cortical neuronal cultures to $35 \mu \mathrm{M}$ Glu or NMDA for $20 \mathrm{~min}$, acute neuronal swelling, breakage in dendrocytes, and the indistinct nuclear shape were observed by phase-contrast microscopy (Figure 1). This neuronal injury became more intense with increase in incubation time, ultimately resulting in enhanced neuronal damage and finally neuronal cell death. The objective of the current research work was to evaluate the neuroprotective effect of the ethanol extract of $S$. baicalensis as claimed in the traditional Chinese medicine, where this plant has been used against various neurological disorders. Our results demonstrated that when the neuronal cell cultures were exposed for $20 \mathrm{~min}$ to Glu $(350 \mu \mathrm{M})$ in the presence of different concentrations of the S.B. extract, the Glu-induced excitotoxicity was dramatically inhibited in a dose-dependent pattern showing maximum inhibition at $100 \mu \mathrm{g} / \mathrm{mL}$ of the extract (Figure 1). The qualitative estimation of Glu-induced neuronal cell death was evaluated by phase-contrast microscopy, whereas the degree of 
neuronal cell death was quantitatively estimated by calculating $\mathrm{LDH}$ release activities given off by the damaged neurons out into the culture media. The $\mathrm{IC}_{50}$ values of the extract were found to be 60.01 and $28.60 \mu \mathrm{g} / \mathrm{mL}$, respectively, for Glu and NMDA-induced excitotoxicity, respectively (Figures 1 and 2).

4.2. Selective Inhibition of NMDA Receptor-Mediated Excitotoxicity. As the Glu-induced excitotoxicity is arbitrated through a number of Glu-receptor subtypes, in order to estimate whether the S.B. extract inhibits the NMDA receptormediated toxicity, the cell cultures were subjected to $350 \mu \mathrm{M}$ NMDA for 20 min. NMDA-induced excitotoxicity is already reported in the literature [22]. In the current study, we found that neuronal damage induced by NMDA and the neuronal deformation was morphologically similar to that produced by Glu. The S.B. extract exhibited a potent inhibition of NMDA-induced excitotoxicity as well. As is evident from the graph (Figure 2), the NMDA-inhibition curve exhibited a more pronounced shift than Glu-inhibition curve, indicating a more powerful and selective inhibitory effect of the extract on NMDA receptor-mediated excitotoxicity. The $\mathrm{IC}_{50}$ value of the extract in this case was found to be $28.6 \mu \mathrm{g} / \mathrm{mL}$. The extract showed a dose-dependent inhibition, and at a concentration of $100 \mu \mathrm{g} / \mathrm{mL}$, almost $90-95 \%$ of the neurons were secured from the excitotoxic insults. As can be seen in Figure 1, after the treatment with $100 \mu \mathrm{g} / \mathrm{mL}$ S.B. extract $+350 \mu \mathrm{M}$ Glu, the neurons showed regular and distinct shape under phase-contrast microscopy unlike in $350 \mu \mathrm{M}$ Glu culture. Thus, these results indicate that the ethanol S.B. extract displays a neuroprotective effect against Glu or NMDA-induced excitotoxic neuronal cell death and more importantly this neuroprotective effect is principally arbitrated through NMDA receptors.

4.3. $\left[{ }^{3} H\right] M D L 105,519$ Binding Studies. In the present study, further experiments were carried out to confirm whether the S.B. extract interacts with the glycine site of NMDA receptor. For this purpose, $\left[{ }^{3} \mathrm{H}\right] \mathrm{MDL} 105,519$ radioligand receptor binding assay was carried out where $\left[{ }^{3} \mathrm{H}\right] \mathrm{MDL} 105,519$ acts as a selective glycine site antagonist. The results indicated that S.B. extract competitively inhibited the binding of $\left[{ }^{3} \mathrm{H}\right] \mathrm{MDL}$ 105,519 to the glycine receptor site (Figure 3 ). It was observed that, at a concentration of $100 \mu \mathrm{g} / \mathrm{mL}$ of the extract, more than $90 \%$ of the binding of $\left[{ }^{3} \mathrm{H}\right] \mathrm{MDL} 105,519$ was displaced by the extract. The $\mathrm{IC}_{50}$ value was found to be $35.1 \mu \mathrm{g} / \mathrm{mL}$.

4.4. $\left[{ }^{3} H\right] M K-801$ Binding Studies. As can be seen in Figure 4, the specific binding of $\left[{ }^{3} \mathrm{H}\right] \mathrm{MK}-801$ was appreciably inhibited by the S.B. extract. The $\mathrm{IC}_{50}$ value of the extract was found to be $65.1 \mu \mathrm{g} / \mathrm{mL}$. At a concentration of $100 \mu \mathrm{g} / \mathrm{mL},\left[{ }^{3} \mathrm{H}\right] \mathrm{MK}-$ 801 binding with the receptor site was around $20 \%$ of the control binding calculated in the absence of the extract. Based on these two radioligand binding assays, we can conclude that the S.B. extract probably inhibits the NMDA receptor by knocking out glycine from its binding site. It has been

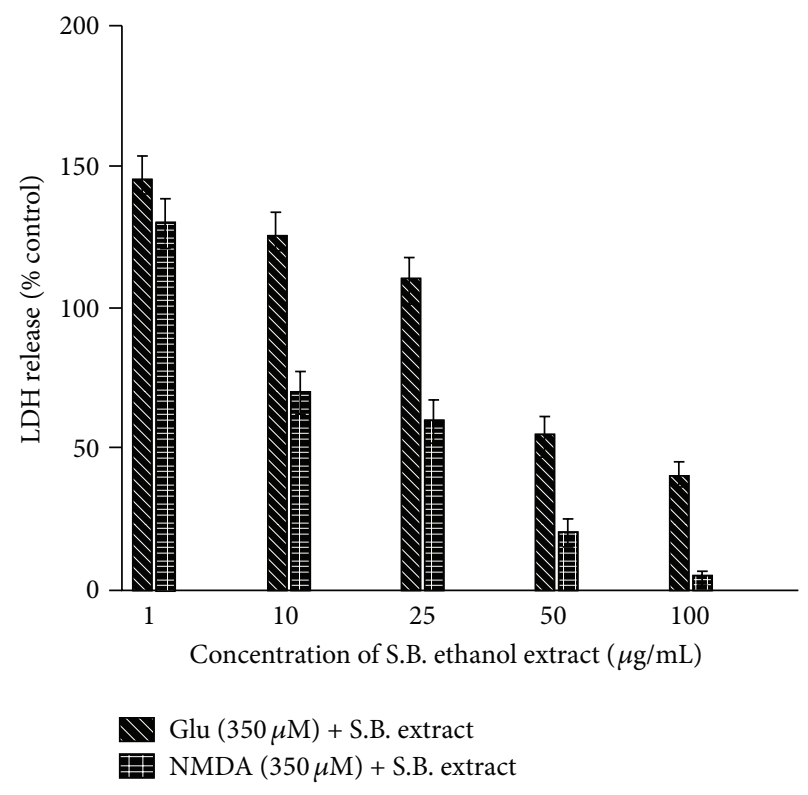

FIGURE 2: Inhibition of N-methyl-D-aspartate (NMDA) or glutamate- (Glu-) induced excitotoxicity by the ethanol extract of Scutellaria baicalensis (S.B.). Lactate dehydrogenase (LDH) activities given off by the damaged neurons into the culture media were measured at 20-24 h after the exposure. Data were calculated as percent of control $\mathrm{LDH}$ activity released into the Glu-treated culture medium. Cultures were exposed for $20 \mathrm{~min}$ to $350 \mathrm{mM} \mathrm{Glu}$ or NMDA in the presence of various concentrations $(1,10,25,50$, and $100 \mu \mathrm{g} / \mathrm{mL}$ ) of the AGR extract and maintained as described in the experimental part.

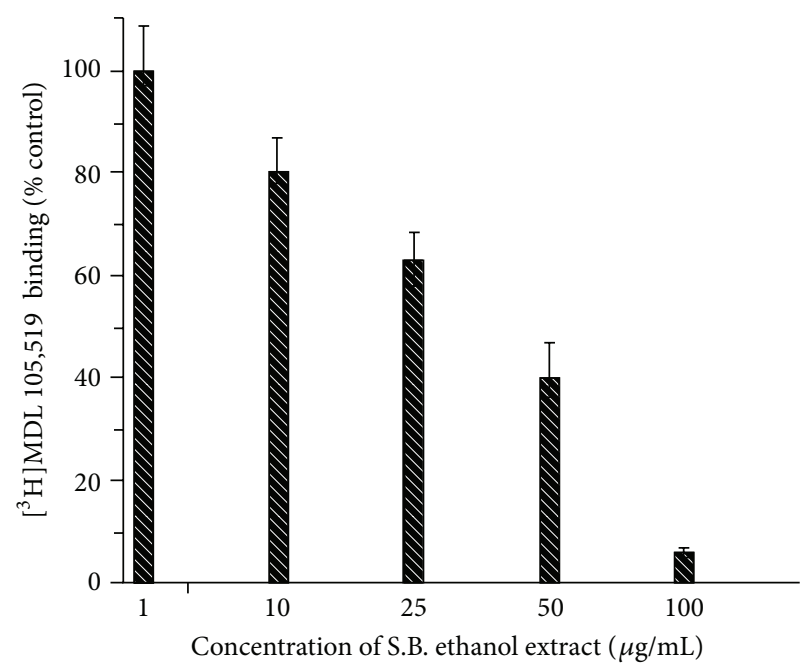

FIGURE 3: Scutellaria baicalensis (S.B.) extract inhibits the specific binding of $\left[{ }^{3} \mathrm{H}\right] \mathrm{MDL} 105,519$ to the glycine site of the N-methyl-Daspartate (NMDA) receptor. Different concentrations of the extract were employed. Nonspecific binding determined in the presence of $2 \mathrm{mM}$ glycine was subtracted from the total binding. Data were calculated as percent of the control binding measured in the absence of the extract. 


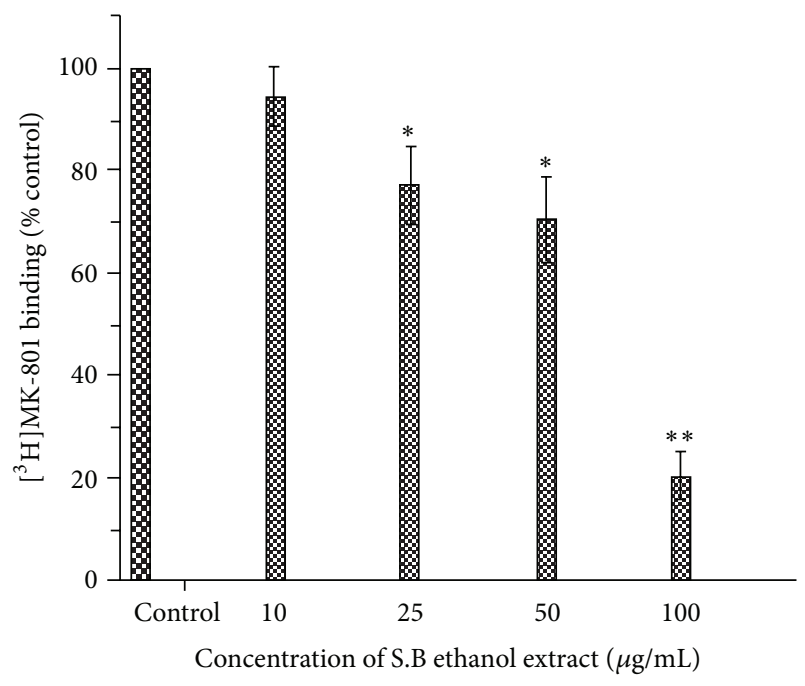

FIgURE 4: The ethanol extract of Scutellaria baicalensis inhibits the binding of $\left[{ }^{3} \mathrm{H}\right] \mathrm{MK}-801$ to the N-methyl-D-aspartate (NMDA) receptor. Different concentrations of the extract (here we used $10,25,50$, and $100 \mu \mathrm{g} / \mathrm{mL}$ ) were employed. Nonspecific binding determined in the presence of $200 \mu \mathrm{M}$ MK-801 was subtracted from the total binding. Data were calculated as percent of the control binding measured in the absence of the extract. Each point represents the mean \pm S.D. ${ }^{*} P<0.05 ;{ }^{* *} P<0.01$ (compared with control binding).

already reported in the literature that assessment of $\left[{ }^{3} \mathrm{H}\right] \mathrm{MK}-$ 801 binding is a hallmark of the functional state of NMDA receptors [23].

4.5. LC-ESI-MSMS Analysis/HPLC Analysis. The phytochemical analysis of the $S$. baicalensis ethanol extract was carried out by LC-ESI-MS in combination with HPLCDAD analytical techniques. The extract was run under both positive and negative ESI-MS conditions and it showed several major and minor ionic fragments. The six chemical constituents identified were baicalein, baicalin, wogonin, wogonoside, scutellarin, and Oroxylin A (Figure 5). These phytochemicals present in the root part of S. baicalensis have already been reported previously in this and other plant species of the Scutellaria genus. The total ion MS chromatogram (TIC), HPLC profile, and HPLC-3D plot are shown in Figures 6, 7, and 8, respectively. Fragmentation of the major peaks was used for the identification of compounds. The identification of the chemical compounds was also carried out by comparing the molecular ion peaks along with the MS fragmentation pattern with those of the literature.

\section{Discussion}

Scutellaria baicalensis Georgi has been reported to contain various flavonoids such as baicalein (5,6,7-trihydroxyflavone), baicalin (baicalein-7-O-glucuronide), and wogonin (5,7-dihydroxy-8-methoxyflavone). These phytochemicals are proven potent antioxidants and have been reported to quench reactive oxygen species (ROS) to protect neuronal cells from oxidative damage in cerebral ischemia/reperfusion. These flavonoids have also been reported to inhibit lipid peroxidation of neuronal membranes and to prevent Glu-induced excitotoxicity. Wogonin, as an inhibitor of the CNS inflammation, has been reported to suppress NO (nitric oxide) production and iNOS (inducible nitric oxide synthase) activation in cultured rat astrocytes. Baicalin, another phytochemical from S. baicalensis, has been reported to enhance neural stem/progenitor cell production and hippocampal dependent neurogenesis in rats following cerebral ischemia when these rats were injected with $50 \mathrm{mg} / \mathrm{Kg}$ daily [24]. Baicalin has also been reported to preserve heat shock protein 70 (HSP70), with the latter being known to exert protective effects in neurons [25-27]. S. baicalensis as such has been shown to exhibit memory enhancing properties against ibotenic acid (toxin), chronic lipopolysaccharide infusion, gamma-irradiation, beta amyloid proteins, ischemia, and so forth [28-31]. Ethanol extract of Scutellaria baicalensis Georgi prevents oxidative damage and neuroinflammation and memorial impairments in artificial senescence mice [32]. The amount of baicalin in Scutellaria is much more than that of baicalein. After oral administration of the aqueous extract of S. baicalensis, baicalein, baicalin, and wogonin are rapidly absorbed. Baicalin is metabolized into baicalein by bacteria prior to intestinal absorption, with the latter metabolite being detected in plasma up to $24 \mathrm{~h}$. In rat, baicalein enters brain crossing blood brain barrier and distributes in cortex, hippocampus, striatum, thalamus, and brain stem in 20 minutes $[33,34]$.

During an ischemic stroke or status epilepticus, brain glutamatergic receptors of the N-methyl-D-aspartate (NMDA) subtype are overactivated. This results in a substantial intracellular calcium rise which triggers a lethal cascade of events leading to neuronal death. NMDA receptor overactivation is also supposed to be implicated in a range of neurodegenerative diseases such as Alzheimer's disease, Huntington's chorea, and AIDS dementia syndrome. In the hunt for neuroprotective agents, NMDA receptor antagonists undoubtedly remain potential therapeutic drugs. In the present study, we identified one such NMDA receptor antagonist (Scutellaria baicalensis ethanol extract) which exhibits neuroprotective effect, and more importantly this neuroprotective action was mainly mediated through NMDA receptors [35].

\section{Conclusion}

In conclusion, our study convincingly demonstrated that the neuroprotective effect of the S.B. ethanol extract on the Glu or NMDA induced excitotoxicity was mediated through the blockade of NMDA receptors. So this extract can act as NMDA receptor antagonist and these may find potential applications for the discovery of neuroprotective agents from plant sources. 
<smiles>O=c1cc(-c2ccccc2)oc2cc(O)c(O)c(O)c12</smiles>

Baicalein<smiles>COc1c(O)cc(O)c2c(=O)cc(-c3ccccc3)oc12</smiles>

Wogonin<smiles>COc1c(O)cc(O)c2c1CC(c1ccccc1)=CC2=O</smiles>

Oroxylin A<smiles>O=C(O)C1O[C@@H](Oc2cc3oc(-c4ccc(O)cc4)cc(=O)c3c(O)c2O)[C@H](O)[C@H](O)[C@H]1O</smiles><smiles>COc1c(O[C@H]2O[C@H](C(=O)O)[C@@H](O)[C@H](O)[C@H]2O)cc(O)c2c(=O)cc(-c3ccccc3)oc12</smiles>

Wogonoside

Baicalin

FIGURE 5: Phytochemical compounds identified in the bioactive ethanol extract of the root of Scutellaria baicalensis Georgi. These compounds were identified using LC-ESI-MS analysis.

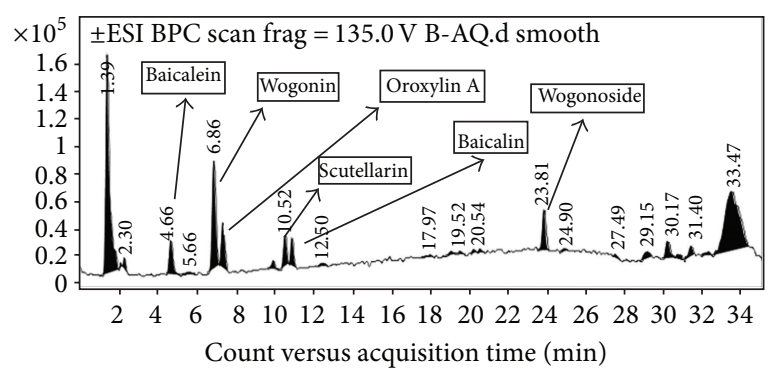

Fragmentor voltage 135 Collision energy 0 Ionization mode ESI

FIGURE 6: LC-MS chromatogram of the bioactive ethanol extract of the root of Scutellaria baicalensis Georgi.

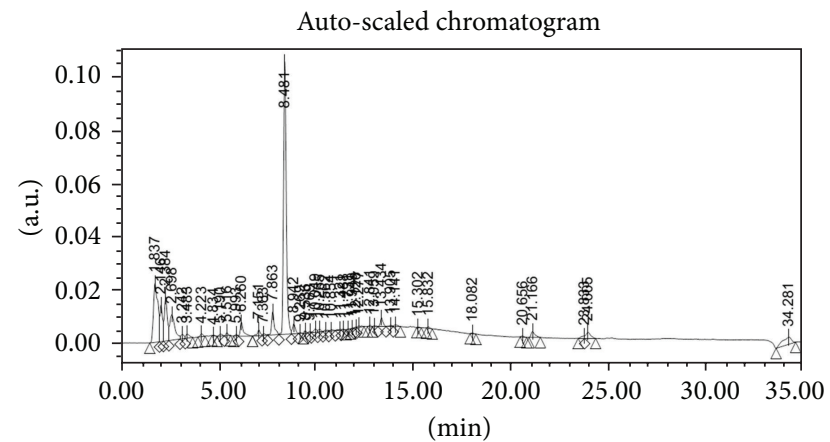

FIGURE 7: HPLC chromatogram of the ethanol extract of Scutellaria baicalensis.

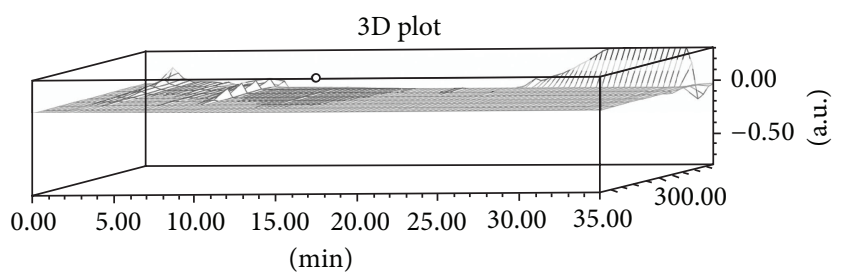

Figure 8: HPLC-3D plot of the ethanol extract of Scutellaria baicalensis.

\section{Conflict of Interests}

The authors declare that there is no conflict of interests regarding the publication of this paper.

\section{Acknowledgments}

This research was supported by Zhejiang Province Traditional Chinese Medicine Scientific Research Plans (Project no. 2013ZA077) and Zhejiang Province Education Department Scientific Research Projects (Project no. Y201328185).

\section{References}

[1] J. W. Olney, "Excitatory transmitter neurotoxicity," Neurobiology of Aging, vol. 15, no. 2, pp. 259-260, 1994. 
[2] G. C. Palmer, "Neuroprotection by NMDA receptor antagonists in a variety of neuropathologies," Current Drug Targets, vol. 2, no. 3, pp. 241-271, 2001.

[3] C. Ikonomidou and L. Turski, "Why did NMDA receptor antagonists fail clinical trials for stroke and traumatic brain injury?” The Lancet Neurology, vol. 1, no. 6, pp. 383-386, 2002.

[4] S. Nakanishi, "Molecular diversity of glutamate receptors and implications for brain function," Science, vol. 258, no. 5082, pp. 597-603, 1992.

[5] E. Gould, H. A. Cameron, and B. S. McEwen, "Blockade of NMDA receptors increases cell death and birth in the developing rat dentate gyrus," Journal of Comparative Neurology, vol. 340, no. 4, pp. 551-565, 1994.

[6] Z. Chen, K. Nihei, H. Tanaka, Y. Uda, and Y. Kabuyama, "Identification of a nitric oxide generation-stimulative principle in Scutellariae radix," Bioscience, Biotechnology, and Biochemistry, vol. 77, no. 3, pp. 657-659, 2013.

[7] S.-B. Yoon, Y.-J. Lee, S. K. Park et al., "Anti-inflammatory effects of Scutellaria baicalensis water extract on LPS-activated RAW 264.7 macrophages," Journal of Ethnopharmacology, vol. 125, no. 2, pp. 286-290, 2009.

[8] W.-H. Huang, A.-R. Lee, and C.-H. Yang, "Antioxidative and anti-inflammatory activities of polyhydroxyflavonoids of Scutellaria baicalensis GEORGI," Bioscience, Biotechnology and Biochemistry, vol. 70, no. 10, pp. 2371-2380, 2006.

[9] F.-M. Ho, Y.-H. Liao, A.-J. Yang et al., "Anti-atherosclerotic action of Ger-Gen-Chyn-Lian-Tang and AMPK-dependent lipid lowering effect in hepatocytes," Journal of Ethnopharmacology, vol. 142, no. 1, pp. 175-187, 2012.

[10] J. J. Lee, T. Kim, W. K. Cho, and J. Y. Ma, "Antithrombotic and antiplatelet activities of Soshiho-tang extract," BMC Complementary \& Alternative Medicine, vol. 13, article 137, 2013.

[11] H. Zhang, Q. Chen, W. Zhou et al., "Chinese medicine injection shuanghuanglian for treatment of acute upper respiratory tract infection: a systematic review of randomized controlled trials," Evidence-Based Complementary and Alternative Medicine, vol. 2013, Article ID 987326, 7 pages, 2013.

[12] G. G. L. Yue, B. C. L. Chan, H.-F. Kwok et al., "Screening for antiinflammatory and bronchorelaxant activities of 12 commonly used Chinese herbal medicines," Phytotherapy Research, vol. 26, no. 6, pp. 915-925, 2012.

[13] W.-H. Huang, P.-Y. Chien, C.-H. Yang, and A.-R. Lee, "Novel synthesis of flavonoids of Scutellaria baicalensis GEORGI," Chemical and Pharmaceutical Bulletin, vol. 51, no. 3, pp. 339340, 2003.

[14] C. Yu, F. Qu, Y. Mao et al., "Different extraction pretreatments significantly change the flavonoid contents of Scutellaria baicalensis," Pharmaceutical Biology, vol. 51, no. 10, pp. 12281235, 2013.

[15] H.-C. Shih, C.-S. Hsu, and L.-L. Yang, "In vitro study of the tocolytic effect of oroxylin A from Scutellaria baicalensis root," Journal of Biomedical Science, vol. 16, article 27, 2009.

[16] G. Liu, N. Rajesh, X. Wang et al., "Identification of flavonoids in the stems and leaves of Scutellaria baicalensis Georgi," Journal of Chromatography B: Analytical Technologies in the Biomedical and Life Sciences, vol. 879, no. 13-14, pp. 1023-1028, 2011.

[17] M. H. Kwok, H. W. Xi, and H. Xue, "Interaction of flavones from the roots of Scutellaria baicalensis with the benzodiazepine site," Planta Medica, vol. 66, no. 1, pp. 91-93, 2000.

[18] H. G. Park, S. Y. Yoon, J. Y. Choi et al., "Anticonvulsant effect of wogonin isolated from Scutellaria baicalensis," European Journal of Pharmacology, vol. 574, no. 2-3, pp. 112-119, 2007.
[19] Z.-J. Zhang, P. Li, Z. Wang et al., "A comparative study on the individual and combined effects of baicalin and jasminoidin on focal cerebral ischemia-reperfusion injury," Brain Research, vol. 1123, no. 1, pp. 188-195, 2006.

[20] T. Priestley, A. L. Horne, R. M. McKernan, and J. A. Kemp, “The effect of NMDA receptor glycine site antagonists on hypoxiainduced neurodegeneration of rat cortical cell cultures," Brain Research, vol. 531, no. 1-2, pp. 183-188, 1990.

[21] J. Cho, J.-Y. Kong, D.-Y. Jeong, K. D. Lee, D.-U. Lee, and B.-S. Kang, "NMDA recepter-mediated neuroprotection by essential oils from the rhizomes of Acorus gramineus," Life Sciences, vol. 68, no. 13, pp. 1567-1573, 2001.

[22] J.-Y. Koh, M. P. Goldberg, D. M. Hartley, and D. W. Choi, "NonNMDA receptor-mediated neurotoxicity in cortical culture," Journal of Neuroscience, vol. 10, no. 2, pp. 693-705, 1990.

[23] D. W. Bonhaus and J. O. McNamara, "N-methyl-D-aspartate receptor regulation of uncompetitive antagonist binding in rat brain membranes: kinetic analysis," Molecular Pharmacology, vol. 34, no. 3, pp. 250-255, 1988.

[24] P.-W. Zhuang, G.-Z. Cui, Y.-J. Zhang et al., "Baicalin regulates neuronal fate decision in neural stem/progenitor cells and stimulates hippocampal neurogenesis in adult rats," CNS Neuroscience \& Therapeutics, vol. 19, no. 3, pp. 154-162, 2013.

[25] R. G. Giffard and M. A. Yenari, "Many Mechanisms for Hsp70 Protection from Cerebral Ischemia," Journal of Neurosurgical Anesthesiology, vol. 16, no. 1, pp. 53-61, 2004.

[26] B. H. Han and D. M. Holtzman, "BDNF protects the neonatal brain from hypoxic-ischemic injury in vivo via the ERK pathway," Journal of Neuroscience, vol. 20, no. 15, pp. 5775-5781, 2000.

[27] Z. Xia, M. Dickens, J. Raingeaud, R. J. Davis, and M. E. Greenberg, "Opposing effects of ERK and JNK-p38 MAP kinases on apoptosis," Science, vol. 270, no. 5240, pp. 1326-1331, 1995.

[28] M. Malek, S. Z. Asl, A. Sarkaki, Y. Farbood, and A. H. Doulah, "The effect of intra-hippocampal injection of growth hormone on spatial learning and memory in animal model of Alzheimer's disease," Pakistan Journal of Biological Sciences, vol. 12, no. 18, pp. 1237-1245, 2009.

[29] H. Heo, Y. Shin, W. Cho, Y. Choi, H. Kim, and Y. K. Kwon, "Memory improvement in ibotenic acid induced model rats by extracts of Scutellaria baicalensis," Journal of Ethnopharmacology, vol. 122, no. 1, pp. 20-27, 2009.

[30] Y. K. Hwang, M. Jinhua, B.-R. Choi et al., "Effects of Scutellaria baicalensis on chronic cerebral hypoperfusion-induced memory impairments and chronic lipopolysaccharide infusioninduced memory impairments," Journal of Ethnopharmacology, vol. 137, no. 1, pp. 681-689, 2011.

[31] S. B. Oh, H. R. Park, Y. J. Jang, S. Y. Choi, T. G. Son, and J. Lee, "Baicalein attenuates impaired hippocampal neurogenesis and the neurocognitive deficits induced by $\gamma$-ray radiation," British Journal of Pharmacology, vol. 168, no. 2, pp. 421-431, 2013.

[32] K. Jeong, Y.-C. Shin, S. Park et al., "Ethanol extract of Scutellaria baicalensis Georgi prevents oxidative damage and neuroinflammation and memorial impairments in artificial senescense mice," Journal of Biomedical Science, vol. 18, article 14, 2011.

[33] L. Zhang, G. Lin, Q. Chang, and Z. Zuo, "Role of intestinal first-pass metabolism of baicalein in its absorption process," Pharmaceutical Research, vol. 22, no. 7, pp. 1050-1058, 2005.

[34] L. Zhang, G. Lin, and Z. Zuo, "Involvement of UDPglucuronosyltransferases in the extensive liver and intestinal 
first-pass metabolism of flavonoid baicalein," Pharmaceutical Research, vol. 24, no. 1, pp. 81-89, 2007.

[35] D. Milhaud, L. Fagni, J. Bockaert, and M. Lafon-Cazal, "Imidazoline-induced neuroprotective effects result from blockade of NMDA receptor channels in neuronal cultures," Neuropharmacology, vol. 39, no. 12, pp. 2244-2254, 2000. 

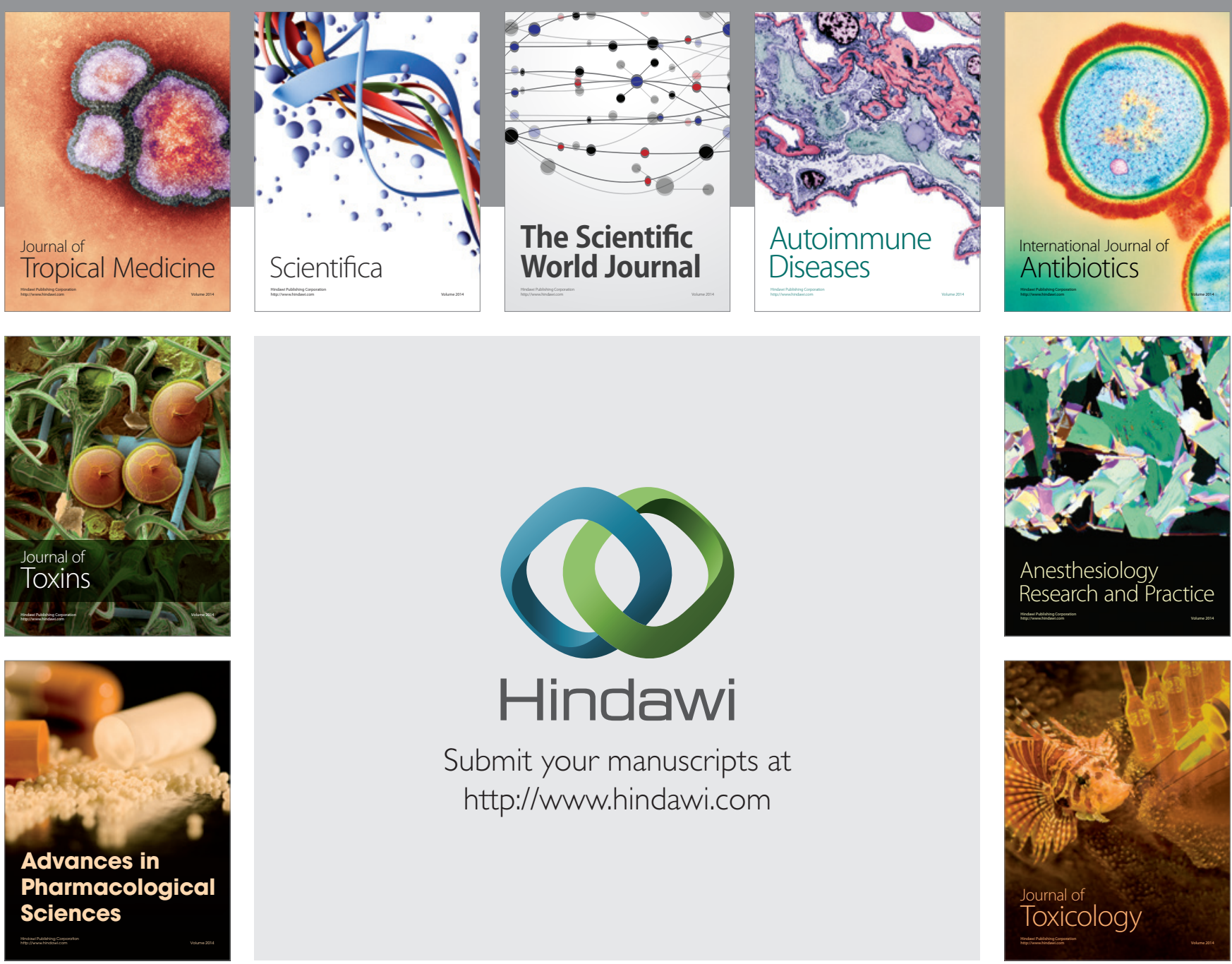

\section{Hindawi}

Submit your manuscripts at

http://www.hindawi.com
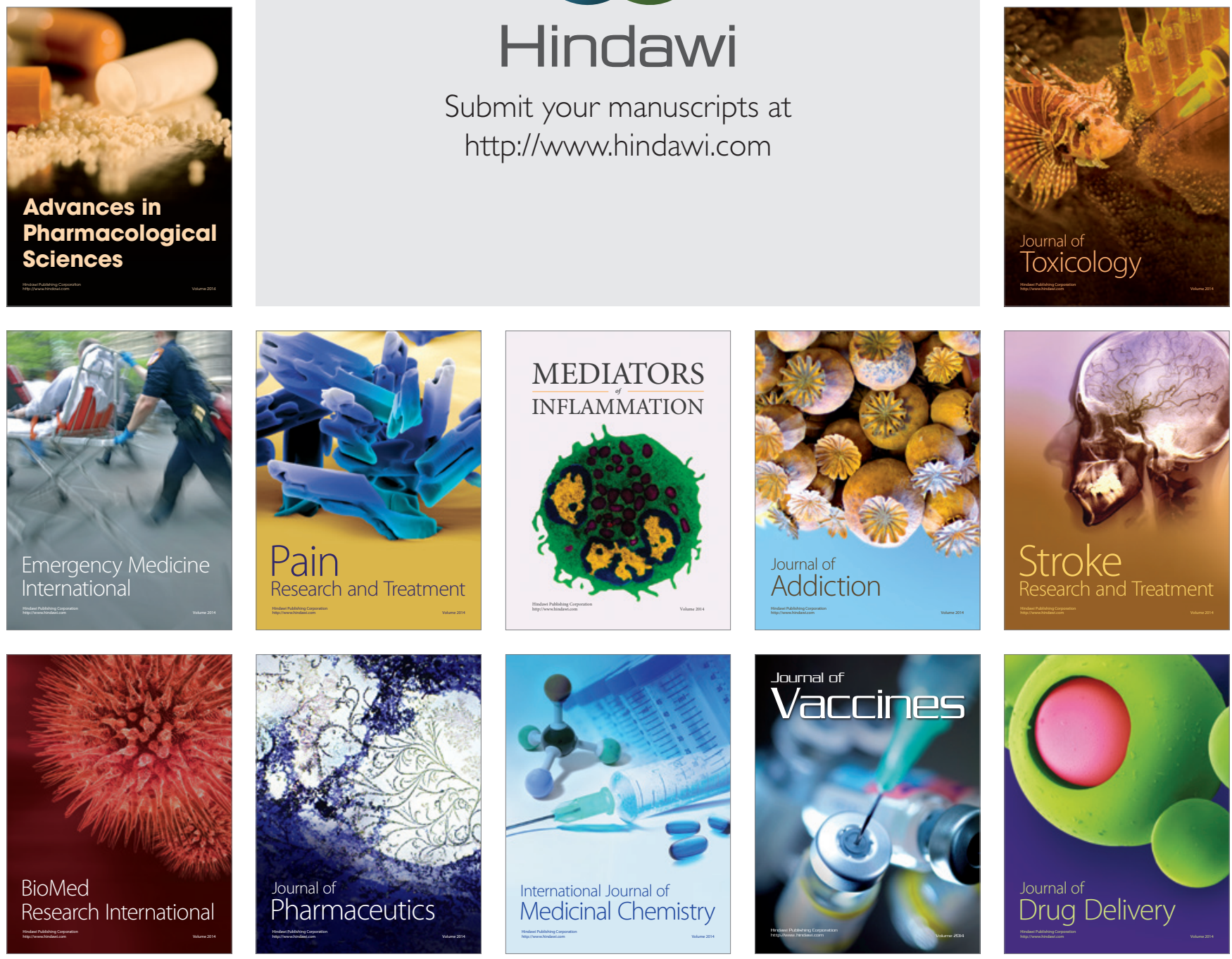